\title{
ADHD symptoms across adolescence: the role of the family and school climate and the DRD4 and 5-HTTLPR genotype
}

\author{
Djûke M. Brinksma ${ }^{1}$ Andrea Dietrich ${ }^{1} \cdot$ Annelies de Bildt ${ }^{1,2} \cdot$ Jan K. Buitelaar ${ }^{3,4} \cdot$ Barbara J. van den Hoofdakker $^{1,5}$. \\ Pieter J. Hoekstra' ${ }^{1}$. . Catharina A. Hartman ${ }^{6}$
}

Received: 17 July 2019 / Accepted: 12 October 2019 / Published online: 18 October 2019

(C) The Author(s) 2019

\begin{abstract}
We examined bidirectional relations between attention-deficit/hyperactivity disorder (ADHD) symptoms and family and school climate, and the possible role of DRD4 and/or 5-HTTLPR genotypes herein. Three-wave longitudinal data of 1860 adolescents (mean ages 11, 13.5, and 16 years) from the general population and clinic-referred cohort of TRacking Adolescents' Individual Lives Survey were used. Using a multigroup Random Intercept Cross-Lagged Panel Model, we tested between-person (i.e., stable trait levels) and within-person (i.e., causal processes) associations across ADHD symptoms, family and school climate, and the extent to which these depended on genotype. Findings indicated no influence of genotype. Results did show significant between-person differences (ADHD symptoms with family climate $r=.38$; and school climate $r=.23, p$ values $<.001$ ), indicating that higher stable levels of ADHD symptoms were associated with a less favorable family and school climate. Regarding within-person causal processes, ADHD symptoms predicted a less favorable family climate in early adolescence $(\beta=.16, p<.01)$, while ADHD symptoms predicted a more favorable family climate in the later phase of adolescence $(\beta=-.11, p<.01)$, a finding which we explain by normative developmental changes during adolescence. Overall, this study showed that negative associations between ADHD symptoms and both family and school climate are largely explained by stable between-person differences. We recommend applying the Random Intercept Cross-Lagged Path Model to developmental data to tease stable associations and change processes apart.
\end{abstract}

Keywords ADHD $\cdot$ Adolescence $\cdot$ Gene-environment interaction $\cdot$ Longitudinal study $\cdot$ Risk and promotive factors

\section{Introduction}

Attention-deficit/hyperactivity disorder (ADHD) is one of the most commonly diagnosed disorders of childhood [1]. Although on average ADHD symptoms decline after

Electronic supplementary material The online version of this article (https://doi.org/10.1007/s00787-019-01424-3) contains supplementary material, which is available to authorized users.

Pieter J. Hoekstra

p.hoekstra@accare.nl

1 Department of Child and Adolescent Psychiatry, University Medical Center Groningen, University of Groningen, Hanzeplein 1, XA10, 9713 GZ Groningen, The Netherlands

2 Accare Child and Adolescent Psychiatry, Groningen, The Netherlands

3 Department of Cognitive Neuroscience, Donders Institute for Brain, Cognition and Behavior, Radboud University Nijmegen Medical Center, Nijmegen, The Netherlands childhood, the course of symptoms differs between individuals (e.g., [2-4]). The course of ADHD symptoms is explained by genetic and environmental influences [5, 6], including family functioning (e.g., [7, 8]). It is well-documented, although based on predominantly cross-sectional studies, that ADHD symptoms and adverse family circumstances may co-occur (e.g., [9-13]). Longitudinal studies, which provide more compelling evidence of cause-effect

4 Karakter Child and Adolescent Psychiatry University Centre, Nijmegen, The Netherlands

5 Department of Clinical Psychology and Experimental Psychopathology, University of Groningen, Groningen, The Netherlands

6 Department of Psychiatry, Interdisciplinary Center Psychopathology and Emotion regulation (ICPE), University Medical Center Groningen, University of Groningen, Groningen, The Netherlands 
relations, have shown in (pre-)school aged boys that a less optimal family environment predicted higher ADHD levels [14]. In addition, in 4-year-old boys, a negative home atmosphere was significantly associated with ADHD symptoms 2.5 years later [15], but it is unknown whether this association holds for adolescents. Furthermore, little is known about the role of a positive environment in the course of ADHD symptoms, despite evidence that individuals living in a supporting environment generally tend to have better developmental outcomes across adolescence [16, 17]. One longitudinal study found that higher levels of parental involvement predicted reduced symptoms of ADHD symptoms in young children [18]. In school age boys, a more optimal family environment predicted lower ADHD symptoms [19, 20]. In recent years, there has been more attention for (prospective) associations between ADHD symptoms and family functioning, but those studies often focused on parental ADHD symptoms rather than the broader family environment (e.g., [21, 22]). Prospective associations between adolescents' ADHD symptoms and the socio-emotional quality of family functioning, which we here refer to as the family climate, are an understudied topic.

The school environment another important environmental factor that may be related to ADHD symptoms over time, has received little research attention, despite the fact that adolescents spent substantial amounts of time at school. In general, it is well known that classroom quality is influential in reducing ADHD symptoms by behavioral school interventions [23], but it is also possible that a negative classroom environment might exacerbating adolescents' risk for elevated ADHD symptoms. It has frequently been reported that individuals with ADHD are more often rejected [24] or bullied by their peers than typically developing adolescents $[25,26]$, which may have negative effects on development. Conversely, friendships may play an important protective role against negative psychosocial outcomes for individuals with ADHD [27]. Apart from peers in the classroom, teachers make a crucial contribution to adolescents' academic and social-emotional outcomes [28, 29], and this may well hold for ADHD symptoms as well. However, students with ADHD exhibit a variety of behaviors in the classroom that may disrupt teaching, increase teacher's experience of stress, and may stand in the way of a supporting school climate [30]. Taken together, these studies suggest that the school climate, here defined as the extent of experienced security and comfort at school by the adolescent, may also affect the ADHD symptom course across adolescence.

Individuals differ in the extent to which they are influenced by the environment. The differential susceptibility theory states that some individuals are sensitive to negative and positive environments $[31,32]$. The dopamine $\mathrm{D} 4$ receptor gene (DRD4) is proposed as one of the genetic susceptibility variants [33]. In the present study, we investigated whether this gene functions as a moderator of the effect of the family and school climate on ADHD symptoms across adolescent development. Gene-environment interaction $(\mathrm{G} \times \mathrm{E})$ studies have shown that individuals carrying the $D R D 47$-repeat are more vulnerable to negative environments and may also benefit more from supportive environments [34, 35]. In relation to the family environment, young children with the $D R D 4$ 7-repeat allele have been shown to be more sensitive to both positive and negative aspects of parenting [33,35]. Another study, focusing on negative family influences, showed that children's DRD4 variants moderated the association between parental inconsistent discipline and the children's ADHD [36]. In relation to the school environment, genetic moderation studies with the DRD4 genotype have examined the influence of peers and teachers in promoting positive development. For example, children with the DRD4 7-repeat allele who experienced little to no peer victimization had lower levels of externalizing behaviors compared to when they experienced high amounts of peer victimization [37]. However, in a previous TRacking Adolescents' Individual Lives Survey (TRAILS) study, in relation to delinquency, DRD4 7-repeat allele carriers were less sensitive to the effects of both peer victimization and social well-being [38]. A similar effect has been found for the association between teacher-student dissatisfaction and rule-breaking behaviors which was stronger for adolescents without the 7-repeat DRD4 non-long carriers [39]. Together these findings suggest that the prospective associations between family and school climate and ADHD studied here may be moderated by $D R D 4$ genotype.

Within the framework of differential susceptibility theory, it is also relevant to investigate another plasticity gene, the 5-HTTLPR genotype [34]. Individuals who are S-allele carriers were found to be more vulnerable to negative environments, but also profited more from a positive environment compared to L-allele homozygotes [40]. One cross-sectional study in youth aged 6-17 years showed that family conflict predicted increased inattention symptoms, whereas family cohesion predicted decreased inattention symptoms, but only for adolescents homozygous for the S-allele [41]. Furthermore, only in S-allele carriers, caregiver-reported peer problems at age 4 predicted ADHD symptoms two years later [42]. This literature thus suggests that the 5-HTTLPR genotype might moderate associations between ADHD symptoms and both the family and school climate.

The present study investigated whether longitudinal bidirectional associations between the family and school climate, and ADHD symptoms across adolescent development (mean ages $11,13.5$, and 16 years) is moderated by the DRD4 and/ or 5-HTTLPR. Using the Random Intercept Cross-Lagged Path Model (RI-CLPM), we aimed to distinguish betweenperson differences (i.e., between stable trait levels) from within-person (causal) processes over time (i.e., in change 
over time $[43,44])$. By partialling out between- and withinperson variance, more adequate inferences can be drawn regarding within-person (causal) processes in development [44], compared to conventional cross-lagged path models $[45,43]$. That is, on one hand, genetic moderation may take place on the stable associations of ADHD symptoms with both family and school climate capturing the entire period of adolescence between ages 11 and 16 (i.e., moderation at the between-person level). On the other hand, genetic moderation may take place at the within-person level, where the application of the RI-CLPM allows for determining genetic moderation is present in within causal-person processes of ADHD influencing the family and school climate or vice versa during adolescence. The latter captures the dynamic interplay between genes and environment on developmental change over the life course [46], which we examined here during adolescence.

In line with most $\mathrm{G} \times \mathrm{E}$ research, we expected that $D R D 4$ 7-repeat carriers and 5-HTTLPR S-allele homozygotes would be more sensitive to the effects of a more favorable family and school climate as indicated by a reduction of ADHD symptoms. Vice versa, we expected also that adolescents with these genetic variants would have higher ADHD symptoms across adolescence in less favorable family and school climates. However, the previous $\mathrm{G} \times \mathrm{E}$ research has been mainly cross section in nature (e.g., [33, 35, 37, 39]) and, furthermore, has not focused on within person change dynamics. Using the RI-CLPM model, we expected $\mathrm{G} \times \mathrm{E}$ effects on both the between-person level and the withinperson level.

\section{Methods}

\section{Sample}

The 1848 participants were from the Tracking Adolescents' Individual Lives Survey (TRAILS) who took part in the first (T1), second (T2), and/or (T3) measurement waves. TRAILS is an ongoing prospective study of Dutch adolescents with the aim to chart and explain the development of mental health from early adolescence into adulthood. The current paper concerns longitudinal data derived from two cohorts, a population-based cohort and a clinic-referred cohort. The population-based cohort comprised young adolescents from five municipalities in the north of The Netherlands, including both urban and rural areas. The inclusion of the clinicreferred cohort, which started 2 years later, was based on referral to the Groningen university child and adolescent psychiatric outpatient clinic, which has a catchment area corresponding with the recruitment areas of the population sample. About $20.8 \%$ had been referred at age $\leq 5$ years, $66.1 \%$ between age 6 and 9 years, and $13.1 \%$ between age
10 and 12 years. The child's parents or legal guardian and adolescents ( $\geq 12$ years) provided both written informed consent prior to each wave, whereas younger participants provided verbal assent. The TRAILS study was approved by the Central Committee on Research Involving Human Subjects (Dutch CCMO). The sampling procedures, descriptive statistics, and response rates of both cohorts are well-documented in papers by De Winter et al. [47] and Oldehinkel et al. [48].

At baseline (T1), 2773 adolescents participated in the population-based $(n=2230)$ and clinic-referred cohort $(n=543)$, with response rates for both cohorts over $80 \%$ for follow-up assessment at T2 and T3. The DRD4 and 5-HTTLPR genotypes were determined for 1873 and 1788 of the 1922 adolescents who had donated DNA. Of those participants, 21 individuals with no data on any ADHD symptoms measurement were excluded. Furthermore, four adolescents had no data on either family or school climate resulting in a final sample size of 1860 participants. Of these participants, 1848 and 1763 adolescents had genetic data on the DRD4 and 5-HTTLPR, respectively.

At T1, 148 (10.7\%) adolescents from the general population subsample had clinical levels of ADHD based on cut-off values from the Achenbach System of Empirically Based Assessment (ASEBA [49]). In the clinic-referred subsample, $225(53.1 \%)$ adolescents had a life-time diagnosis of ADHD, based on the Diagnostic Interview Schedule for Children (DISC-IV parent version [50]).

\section{Measures}

ADHD symptoms At all three waves, we used the seven item DSM-IV-Oriented subscale Attention-Deficit/Hyperactivity Problems of the Child Behavioral Checklist $[51,52]$ as a measure of ADHD symptoms. Items were scored by parents on a 3-point Likert-scale ranging from 0 ('not true') to 2 ('very true or often true').

Family climate Family climate was measured at T1, T2, and T3 by the General Functioning scale of the McMaster Family Assessment Device (FAD [53]). This parent-reported scale is used to assess family functioning, including statements about family communication and support (rating on a 4-points Likert scale ('strongly disagree'-'strongly agree'; 12 items $\alpha \geq 0.85$ at all times for both cohorts). Example items are 'In times of crisis we can turn to each other for support' and 'Individuals are accepted for what they are'. A low score on the scale indicates a healthy family climate; a high score represents a dysfunctional family climate.

School climate To measure the adolescent's experienced school climate, we used items from two scales of the Social Production Functions (SPF; see [54, 55]). The selected items from the two scales measured social support from the teacher and classmates reflecting affection and 
behavioral confirmation (rating on a 5-points Likert scale ('never'-'always'). The child rated social support from teachers originally consisted of 11 (T1 and T2) or 12 items (T3). Whereas at $\mathrm{T} 1$ and $\mathrm{T} 2$, the scale in measuring the experienced social support from classmates was a combination of friends and classmates (originally 17 items), at T3 questions only referred to classmates (originally 11 items). On this last scale we excluded the items about friends at $\mathrm{T} 1$ and $\mathrm{T} 2$. To minimize a positively biased school climate rating especially in adolescents with ADHD (i.e., positive illusory bias [56]), we focused on the most concrete items and excluded subjective items of both scales (e.g., 'most classmates like to do things with me'; 'most teachers like me'). Example items that were kept are 'My teacher/most teachers I can really trust' and 'Most of my classmates help me when there is a problem'. Next, we created a mean score of seven items reflecting school climate and scores were then transformed such that, in line with the family climate rating, a low score indicates a healthy school climate and a high score a dysfunctional school climate. Internal consistency of the seven item school climate rating was acceptable to good (Cronbach's $\alpha$ at T1: .81; at T2: .76, and at T3: .76).

Genotyping DNA was extracted from blood samples ( $n=1525)$ or buccal swabs with a Cytobrush $(n=335)$ using a manual salting out procedure as described by Miller et al. [57] and was collected at T2 for the clinic-referred cohort and at T3 for the population-based cohort. Genotyping of the length polymorphisms DRD4 was done at the Research lab for Multifactorial Diseases within the Human Genetics department of the Radboud University Nijmegen Medical Centre in Nijmegen, The Netherlands. The 48 bp direct repeat polymorphism in exon 3 of $D R D 4$ was genotyped on the Illumina BeadStation 500 platform (Illumina.). Three percent blanks and duplicates between plates were taken along as quality controls during genotyping. Determination of the length of the alleles was performed by direct analysis on an automated capillary sequencer (ABI3730, Applied Biosystems, Nieuwerkerk a/d IJssel, The Netherlands) using standard conditions. Call rate for DRD4 was $99.4 \%$.

Genotyping of the length polymorphisms 5-HTTLPR by simple sequence length analysis (call rate $91.6 \%$ ) and the SNP rs25331 (A/G SNP in L 5-HTTLPR) by a custom-made TaqMan assay (Applied Biosystems; call rate 96.5\%) was also done at the Research lab for Multifactorial Diseases within the Human Genetics department of the Radboud University Nijmegen Medical Centre in Nijmegen, The Netherlands. Concordance between DNA replicates showed an accuracy of $100 \%$. All $l g$ alleles were recoded into S, because it has been shown that this polymorphism represents low serotonin expression comparable to the $\mathrm{S}$ allele [58], while la was recoded as L. Based on these alleles, we refer to the functionality of the expressed transporter as low (SS), intermediate (LS), and high (LL) expression. Given previous
$\mathrm{G} \times \mathrm{E}$ research examining (un)supportive environments of individuals [31,34], we considered the 7-repeat allele of the DRD4 gene and the SS-allele of the 5-HTTLRPR gene as the 'plasticity' alleles.

ADHD medication use Methylphenidate, dexamphetamine, and atomoxetine were coded as $0=$ no use or $1=$ use of any of these three, at any time in the preceding year at T1, $\mathrm{T} 2$, or T3. This variable served as a covariate. The RI-CLPM corrects for stable covariates (e.g., sex, socio-economic status) in the random intercepts.

\section{Data analyses}

Using Mplus [59] two RI-CLPM [43, 44] multigroup analyses were fitted to the data to examine longitudinal associations from $\mathrm{T} 1$ to $\mathrm{T} 2$ (2 year-follow-up) and from $\mathrm{T} 2$ to T3 (3 year follow-up) between ADHD symptoms, family climate, and school climate, for DRD4 and 5-HTTLPR genotypes, separately. Model fit was evaluated based on the Chi square $\left(\chi^{2}\right)$ goodness-of-fit test, the Comparative Fit Index (CFI), and the root-mean-square of approximation (RMSEA). Values for the CFI should preferably be larger than .95 [60], and RMSEA should be below .08, and preferably below .05 [61]. For nested model comparisons we used $\Delta \chi^{2}$ difference tests [62]. Missing data were handled using the full information maximum likelihood (FIML) method.

Before model fitting, we calculated intra-class correlations (ICC; as is common in multi-level modeling) to examine the extent to which there was variance at the betweenperson and within-person level. Figure 1 represents the RI-CLPM as fitted to our data (for further descriptions of the RI-CLPM model, see [43, 44], which was modelled for DRD4 and 5-HTTLPR separately. In the RI-CLPM the between-person stable variance is modelled separately from within-person fluctuations over time. In this way, findings from the group level (i.e., between-person level) can, therefore, not mistakenly be interpreted as causes and effects on the individual (i.e., within-person level) level. To this end, the observed scores of our three main constructs at the three time points (i.e., ADHD symptoms, family, and school climate) and of our control variable (i.e., ADHD medication) were regressed on their own latent factors with the loadings constrained at one. The variances of the observed variables were constrained at zero, to capture all variance of the observed measures by both between-person and within-person latent variables. Next, four latent random intercepts were specified (i.e., for ADHD symptoms, family climate, school climate, and ADHD medication, separately) by constraining factor loadings at one. These latent random intercepts, which represent stable (i.e., stable trait level) between-person differences, were allowed to correlate. With this between-person stable variance separated out, the remaining variance represents the within-person variation 


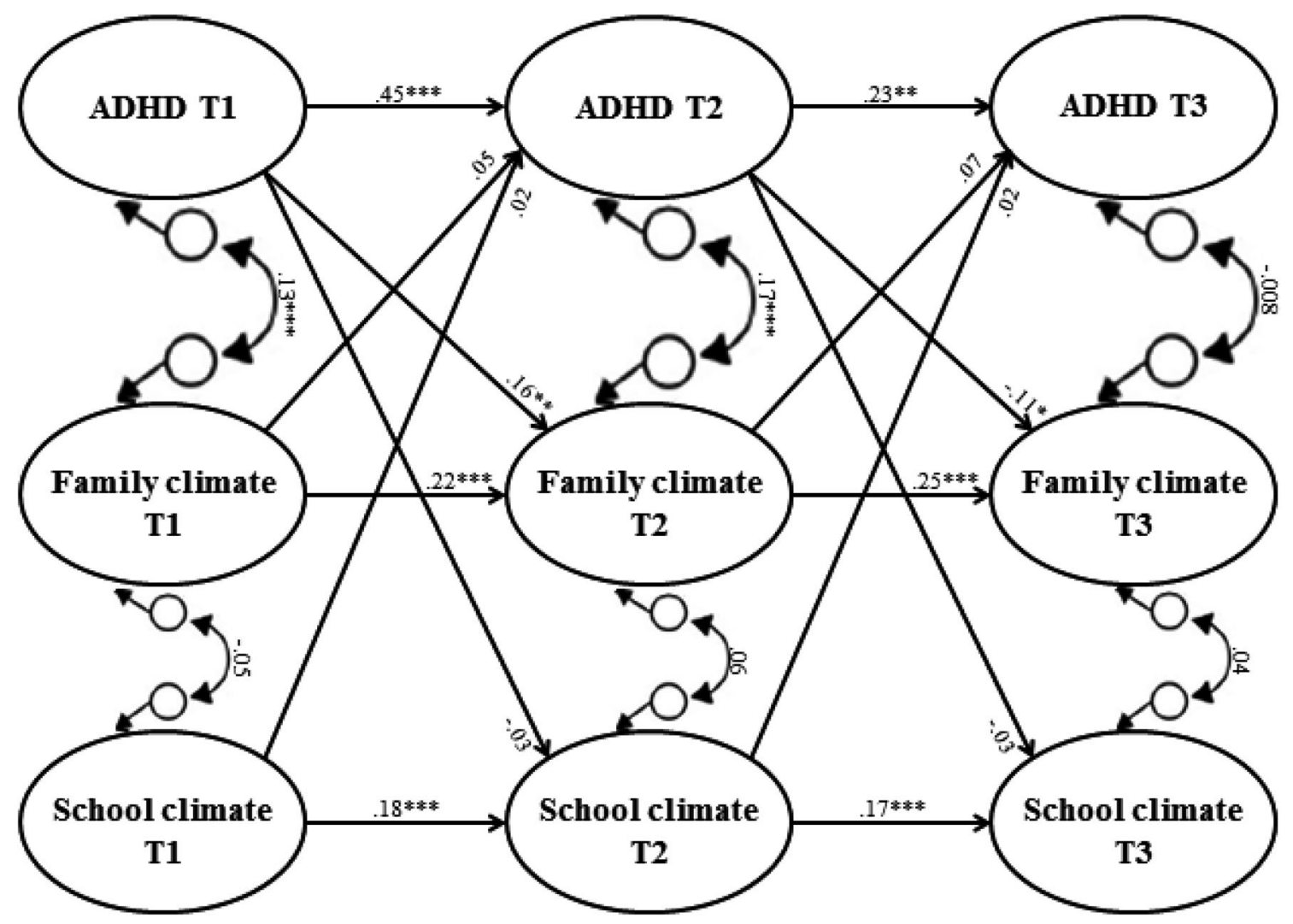

Fig. 1 Standardized path coefficients of within-person level from the random intercept cross-lagged panel model for the associations between ADHD symptoms and family and school climate across ado-

(i.e., fluctuations) over time enabling us to understand possible (causal) processes between ADHD symptoms and both family and school climate and possibly the covariate ADHD medication use. within-person deviations are based on the differences of a persons' expected score (i.e., the individual's position in the population taking into account normative development) and the actual score on a construct. On the one hand, these within-person fluctuations are modelled by autoregressive paths (i.e., extent to which within-person deviations from the expected score can be predicted by within-person deviations from the expected score at a former time point; this reflects carry-over effects, which can both be negative and positive). On the other hand, within-person fluctuations are modeled by cross-lagged paths [i.e., extent to which within-person fluctuations (e.g., family climate) are predicted by within-person fluctuations in another construct (e.g., ADHD) at the previous time-point]. Furthermore, within-person correlations at time 1 between the four different constructs were modelled, representing the extent to which within-person deviations from the expected score in one construct at time 1 was associated with the withinperson deviations from the expected score of the other three constructs at time 1 . Finally, correlated residuals at time lescence while controlling for ADHD medication at all time points. $A D H D$ attention-deficit/hyperactivity disorder symptoms. ${ }^{*} p<.05$, $* * p<.01$, and $* * * p<.001$ indicate significant path coefficients

2 and time 3 (i.e., correlated dynamic errors), model the extent to which within-person fluctuations in one construct are associated with within-person fluctuations in one of the other three constructs at the same time point (see for further explanation $[43,44]$. The online supplement contains further details about subsequent model fitting.

\section{Results}

\section{Descriptive statistics}

The characteristics of the study sample are shown in Table 1, descriptives of the allelic variation of the DRD4 and 5-HTTLPR genotype are displayed in Supplementary Table 1. Intercorrelations among ADHD symptoms across the three time points were high ( $r$ values ranging from .69 to .81 , all $p$ values $<.001)$, as were correlations among family climate ( $r$ values ranging from .43 to .59 , all $p$ values $<.001$ ), but they were small-to-moderate for school climate ( $r$ values ranging from .20 to .43 , all $p$ values $<.001$ ), for all variants of the DRD4 and 5-HTTLPR genotype. Of note, the correlations between ADHD symptoms and school climate 
Table 1 Sample characteristics of the study sample $(n=1860)$

\begin{tabular}{lcccc}
\hline & Total sample & T1 & T2 & T3 \\
\hline Descriptives & & & & \\
$\quad$ Population-based cohort $(\%)$ & $1436(77.2 \%)$ & & & \\
Male gender $(\%)$ & $966(51.9 \%)$ & & $13.62(.62)$ & $16.16(.69)$ \\
Age in years, $M(S D)$ & $11.09(.55)$ & $224(12.0 \%)$ & $172(9.2 \%)$ \\
ADHD medication use ${ }^{\mathrm{a}}, N(\%)$ & $198(10.6 \%)$ & & \\
Main variables & & & \\
ADHD symptoms & & & \\
Family climate $^{\mathrm{c}}, \mathrm{M}(\mathrm{SD})$ & & $0.68(.53)$ & $0.54(.50)$ & $0.48(.46)$ \\
School climate $^{\mathrm{d}}, \mathrm{M}(\mathrm{SD})$ & $1.80(.38)$ & $1.68(.41)$ & $1.67(.41)$ \\
\hline
\end{tabular}

$A D H D$ attention-deficit/hyperactivity disorder

${ }^{a}$ Methylphenidate, dexamphetamine and atomoxetine use at any time during the past year

${ }^{b}$ Mean of 7-items DSM-IV-oriented ADHD subscale of the CBCL (Achenbach [51]; score range 0-2)

${ }^{\mathrm{c}}$ Mean of 12-item Family Functioning scale of the FAD (Epstein et al. [53]; score range 0-4)

${ }^{\mathrm{d}}$ Mean of seven selected items of the teacher and classmates subscales of the Social Production Functions (SPF [54, 55]; score range 0-5) at all time points were small ( $r$ values ranging from -.006 to $.15, p$ values between <.001 and .90), whereas ADHD symptoms and family climate were more strongly correlated ( $r$ values ranging from .19 to .37 , all $p$ values $<.001$ ). There were no significant gene-environment correlations ( $p$-values $>.05)$.

\section{RI-CLPM}

The ICC for ADHD symptoms was .737 indicating that $73.7 \%$ of the variance in the three measures of ADHD symptoms over time is explained by differences between persons (i.e., stable trait level) over time. The remaining variance of $26.3 \%$ is explained by fluctuations within a person (i.e., in change over time). The ICCs for family climate, school climate, and covariate ADHD medication were .508, .285, and .690 , respectively.

DRD4 genotype After it was demonstrated that there were no relations between family and school climate $\left[\Delta \chi^{2}(8)=11.64, p=.17\right.$; fit unconstrained model $\chi^{2}(12)=9.70, \mathrm{CFI}=1.000$, RMSEA $\left.=.000(.000-.029)\right]$, we constrained these relations to zero, and subsequently performed model selection of which the first step was aimed at model simplification (Table 2: step 1.a to 1.c). Constraining the association between ADHD medication and family climate at the between-person level yielded the most substantial misfit in the model; these associations were, therefore, freely estimated. Longitudinal invariance was examined in step 2. In the first part of step 2 (step 2.1.a and 2.1.c), we found that the within-person stability paths of ADHD medication were not equal across time. In the second part of step 2 (step 2.2.1.a to 2.2.3.c), we separately tested whether the within-person stability paths of ADHD symptoms, correlated change between ADHD symptoms and family climate, and cross-lagged paths of ADHD symptoms predicting family climate were different over time. Only when $\Delta \chi^{2}$ was not significant, were the corresponding paths considered equal across time and thereafter constrained to as such. In the third step, not included in Table 2, we found no differences for individuals with and without the 7-repeat of the DRD4 genotype across all study variables at both the between-person and within-person level. The results of the within-person differences of this final model across the DRD4 differences showed good model fit $\left[\chi^{2}(97)=91.981\right.$, $\mathrm{CFI}=1.000, \mathrm{RMSEA}=.000(.000-.016)]$ and are presented in Supplementary Figure 1.

5-HTTLPR genotype In analyzing 5-HTTLPR genotype differences between ADHD symptoms and both family and school climate, we applied the same procedure as when examining moderation of the DRD4 genotype. Table 3 presents the steps of model selection and shows two important issues. First, in examining longitudinal invariance across all paths of ADHD medication (Table 3: step 2.1.b), we reached no convergence presumably caused by large misfit in the stability paths of ADHD medication. The large misfit was indicated when comparing the unconstrained model (Table 3: step 2.1.a) with a model, where only the ADHD medication stability paths over time were constrained $\left[\Delta \chi^{2}(3)=346.84, p<.001\right]$. We, therefore, freely estimated the stability paths, whereas other all ADHD medication paths were constrained over time (Table 3: step 2.1.c); this resulted in a non-significant difference with the unconstrained model. After examining longitudinal invariance, we checked for 5-HTTLPR genotype differences. Compared to the $D R D 4$ genotype model, the stability paths of the school climate had to be freed across time. However, no moderation of the 5-HTTLPR genotype on these additionally freed stability paths were found. Further inspection of 
Table 2 Model fit comparisons of selected models in model simplification for the DRD4 genotype

\begin{tabular}{|c|c|c|c|c|c|c|c|c|}
\hline & \multicolumn{4}{|c|}{ Model fit indices } & \multicolumn{4}{|c|}{ Model comparison test } \\
\hline & $\chi^{2}$ & $d f$ & CFI & RMSEA & & $\Delta \chi^{2}$ & $\Delta d f$ & $p$ \\
\hline \multicolumn{9}{|l|}{ Step 1.a } \\
\hline Unconstrained model & 21.06 & 20 & 1.000 & $.008(.000-.031)$ & & & & \\
\hline \multicolumn{9}{|l|}{ Step 1.b } \\
\hline Constrained model & 74.50 & 52 & 0.996 & $.022(.009-.033)$ & 1.b vs. $1 . \mathrm{a}$ & 53.30 & 32 & .01 \\
\hline \multicolumn{9}{|l|}{ Step 1.c } \\
\hline Freely estimated: $\mathrm{BP}_{\mathrm{ADHD}}$ medication-family climate & 53.41 & 50 & 0.999 & $.009(.000-.024)$ & 1.c vs. 1.a & 32.34 & 30 & .35 \\
\hline \multicolumn{9}{|l|}{ Step 2.1.a } \\
\hline Unconstrained model ADHD medication & 53.41 & 50 & 0.999 & $.009(.000-.024)$ & & & & \\
\hline \multicolumn{9}{|l|}{ Step 2.1.b } \\
\hline Constrained model ADHD medication & 241.64 & 58 & 0.968 & $.060(.052-.068)$ & 2.1.b vs. 2.1.a & 204.71 & 8 & $<.001$ \\
\hline \multicolumn{9}{|l|}{ Step 2.1.c } \\
\hline Freely estimated: $\mathrm{WP}_{\text {Stability path ADHD medication }}$ & 63.91 & 56 & 0.999 & $.012(.000-.025)$ & 2.1.c vs. 2.1.a & 8.98 & 6 & .18 \\
\hline \multicolumn{9}{|l|}{ Step 2.2.1.a } \\
\hline Unconstrained model & 63.61 & 56 & 0.999 & $.012(.000-.025)$ & & & & \\
\hline \multicolumn{9}{|l|}{ Step 2.2.1.b } \\
\hline Constrained model & 97.31 & 62 & 0.994 & $.026(.015-.035)$ & 2.2.1.b vs. 2.2.1.a & 33.70 & 6 & $<.001$ \\
\hline \multicolumn{9}{|l|}{ Step 2.2.1.c } \\
\hline Freely estimated: $\mathrm{WP}_{\text {Stability path ADHD symptoms }}$ & 64.89 & 60 & 0.999 & $.010(.000-.023)$ & 2.2.1.c vs. 2.2.1.a & 1.24 & 4 & .87 \\
\hline \multicolumn{9}{|l|}{ Step 2.2.2.a } \\
\hline Unconstrained model & 64.89 & 60 & 0.999 & $.010(.000-.023)$ & & & & \\
\hline \multicolumn{9}{|l|}{ Step 2.2.2.b } \\
\hline Constrained model & 79.77 & 66 & 0.998 & $.015(.000-.026)$ & 2.2.2.b vs. 2.2.2.a & 16.54 & 6 & .01 \\
\hline \multicolumn{9}{|l|}{ Step 2.2.2.c } \\
\hline Freely estimated: $\mathrm{WP}_{\text {Correlated change } \mathrm{ADHD} \text { symptoms-family climate }}$ & 67.34 & 76 & 0.999 & $.008(.000-.022)$ & 2.2.2.c vs. 2.2.2.a & 2.33 & 4 & .68 \\
\hline \multicolumn{9}{|l|}{ Step 2.2.3.a } \\
\hline Unconstrained model & 67.34 & 76 & 0.999 & $.008(.000-.022)$ & & & & \\
\hline \multicolumn{9}{|l|}{ Step 2.2.3.b } \\
\hline Constrained model & 98.10 & 72 & 0.996 & $.020(.008-.030)$ & 2.2.3.b vs. 2.2.3.a & 35.50 & 8 & $<.001$ \\
\hline \multicolumn{9}{|l|}{ Step 2.2.3.c } \\
\hline Freely estimated: $\mathrm{WP}_{\text {Cross-lagged path } \mathrm{ADHD} \text { symptoms-family climate }}$ & 72.12 & 70 & 1.000 & $.006(.000-.021)$ & 2.2.3.c vs. 2.2.3.a & 4.73 & 6 & .58 \\
\hline
\end{tabular}

$C F I$ Comparative Fit Index, RMSEA root mean squared error of approximation, $A D H D$ attention-deficit/hyperactivity disorder, $B P$ betweenperson level, $W P$ within-person level

these paths after constraining the model to be equal across groups showed no inferior fit $\left[\Delta \chi^{2}(1)=0.07, p=.78\right]$ when the stability paths of family climate were variant instead of invariant over time. Therefore, stability path of school climate were subsequently constrained to be equal over time. Comparable with the DRD4 genotype model, we did not find moderation of the 5-HTTLPR genotype across all constructs at both the between-person and within-person level. In Supplementary Figure 2, the results of the within-person differences of this final model are presented, showing good model fit $\left[\chi^{2}(159)=149.826, \mathrm{CFI}=1.000, \mathrm{RMSEA}=.000\right.$ (.000-.016)].

Overall model Since we did not find moderation of the DRD4 and 5-HTTLPR genotypes, results on the associations between ADHD symptoms and the family and school climate are shown for the total sample. Figure 1 illustrates the within-person differences between ADHD symptoms and the family and school climate independent of genotype for all participants $(n=1863)$ with good model fit $\left[\chi^{2}(35)=43.87, \mathrm{CFI}=0.999, \mathrm{RMSEA}=.012(.000-.021)\right]$. At the between-person level, there were small-to-moderate correlations between the stable traits of ADHD symptoms with family climate $(r=.38, p<.001)$ and school climate $(r=.23, p<.001)$. Thus, higher levels of ADHD symptoms across the three measurement waves coincide with less favorable family and school climates (and lower levels of ADHD symptoms with more favorable family and school climates). Family and school climate were positively correlated $(r=.18, p<.001)$. Results further indicate a substantial stable association of ADHD medication with ADHD 
Table 3 Model fit comparisons of selected models in model simplification for the 5-HTTLPR genotype

\begin{tabular}{|c|c|c|c|c|c|c|c|c|}
\hline & \multicolumn{4}{|c|}{ Model fit indices } & \multicolumn{4}{|c|}{ Model comparison test } \\
\hline & $\chi^{2}$ & $d f$ & CFI & RMSEA & & $\Delta \chi^{2}$ & $\Delta d f$ & $p$ \\
\hline \multicolumn{9}{|l|}{ Step 1.a } \\
\hline Unconstrained model & 19.75 & 30 & 1.000 & $.000(.000-.011)$ & & & & \\
\hline \multicolumn{9}{|l|}{ Step 1.b } \\
\hline Constrained model & 100.70 & 78 & 0.996 & $.022(.004-.034)$ & 1.b vs. $1 . \mathrm{a}$ & 82.12 & 48 & .002 \\
\hline \multicolumn{9}{|l|}{ Step 1.c } \\
\hline Freely estimated: $\mathrm{BP}_{\mathrm{ADHD}}$ medication-family climate & 74.44 & 75 & 1.000 & $.005(.000-.023)$ & 1.c vs. $1 . \mathrm{a}$ & 54.68 & 45 & .15 \\
\hline \multicolumn{9}{|l|}{ Step 2.1.a } \\
\hline Unconstrained model ADHD medication & 74.44 & 75 & 1.000 & $.005(.000-.023)$ & & & & \\
\hline \multicolumn{9}{|l|}{ Step 2.1.b } \\
\hline Constrained model ADHD medication & \multicolumn{4}{|c|}{ No convergence } & \multicolumn{4}{|l|}{ No convergence } \\
\hline \multicolumn{9}{|l|}{ Step 2.1.c } \\
\hline Freely estimated: $\mathrm{WP}_{\text {Stability path } \mathrm{ADHD} \text { medication }}$ & 78.20 & 84 & 1.000 & $.000(.000-.019)$ & 2.1.c vs. 2.1.a & 5.58 & 9 & .78 \\
\hline \multicolumn{9}{|l|}{ Step 2.2.1.a } \\
\hline Unconstrained model & 78.20 & 84 & 1.000 & $.000(.000-.019)$ & & & & \\
\hline \multicolumn{9}{|l|}{ Step 2.2.1.b } \\
\hline Constrained model & 131.20 & 93 & 0.994 & $.026(.015-.036)$ & 2.2.1.b vs. 2.2.1.a & 62.78 & 9 & $<.001$ \\
\hline \multicolumn{9}{|l|}{ Step 2.2.1.c } \\
\hline Freely estimated: $\mathrm{WP}_{\text {Stability path ADHD symptoms }}$ & 91.57 & 91 & 1.000 & $.005(.000-.023)$ & 2.2.1.c vs. 2.2.1.a & 15.41 & 6 & .02 \\
\hline \multicolumn{9}{|l|}{ Step 2.2.1.d } \\
\hline Freely estimated: $\mathrm{WP}_{\text {Stability path school climate }}$ & 81.97 & 87 & 1.000 & $.000(.000-.020)$ & 2.2.1.d vs. 2.2.1.a & 3.90 & 3 & .27 \\
\hline \multicolumn{9}{|l|}{ Step 2.2.2.a } \\
\hline Unconstrained model & 81.97 & 87 & 1.000 & $.000(.000-.020)$ & & & & \\
\hline \multicolumn{9}{|l|}{ Step 2.2.2.b } \\
\hline Constrained model & 101.95 & 96 & 0.999 & $.010(.000-.025)$ & 2.2.2.b vs. 2.2.2.a & 22.33 & 9 & .008 \\
\hline \multicolumn{9}{|l|}{ Step 2.2.2.c } \\
\hline Freely estimated: $\mathrm{WP}_{\text {Correlated change ADHD symptoms-family climate }}$ & 86.93 & 93 & 1.000 & $.000(.000-.019)$ & 2.2.2.c vs. 2.2.2.a & 4.87 & 6 & .56 \\
\hline \multicolumn{9}{|l|}{ Step 2.2.3.a } \\
\hline Unconstrained model & 86.93 & 93 & 1.000 & $.000(.000-.019)$ & & & & \\
\hline \multicolumn{9}{|l|}{ Step 2.2.3.b } \\
\hline Constrained model & 120.02 & 105 & 0.997 & $.016(.000-.027)$ & 2.2.3.b vs. 2.2.3.a & 35.77 & 12 & $<.001$ \\
\hline \multicolumn{9}{|l|}{ Step 2.2.3.c } \\
\hline Freely estimated: $\mathrm{WP}_{\text {Cross-lagged path } \mathrm{ADHD} \text { symptoms-family climate }}$ & 96.13 & 102 & 1.000 & $.000(.000-.019)$ & 2.2.3.c vs. 2.2.3.a & 9.23 & 9 & .42 \\
\hline
\end{tabular}

For abbreviations see Table 2

symptoms $(r=.54, p<.001)$ and a less favorable family climate $(r=.23, p=.001)$.

After the stable 'trait-variance' of ADHD symptoms, family climate, school climate, and medication use were partialled out of the model, we found small-to-large within-person changes over time. First, all within-person stability paths of school and family climate were significant and invariant over time. However, the within-person stability paths of ADHD symptoms were not equal over time, since betas were larger from $\mathrm{T} 1$ to $\mathrm{T} 2$ than from $\mathrm{T} 2$ to $\mathrm{T} 3$. This suggests that as adolescents grow older, they are approaching their expected score. Second, there was a small positive correlation between ADHD symptoms and family climate at T1. This was about half as strong as the stable between-person differences suggesting that most of the variance in the data can be accounted for by trait-like rather than state-like associations (although these associations may, of course, still be confounded by currently not studied variables). Third, the correlated changes between ADHD symptoms and family climate were differentiated between T2 and T3. The significantly correlated residuals at $\mathrm{T} 2$ showed that the withinperson fluctuations in ADHD symptoms was associated with the within-person fluctuations in family climate. This finding indicates that when an individual's level of ADHD symptoms increases between two adjacent measurements, the individual's family climate becomes less favorable (or vice versa). Note that this is a correlation between dynamic errors; they are not due to the change in either study variable 
from 2 years earlier, nor by medication use which is part of the model, but rather by an un-modelled time-variant third factor. This association represented by the correlated change was absent at T3. Finally, the within-person cross-lagged paths of ADHD symptoms in predicting the family climate were different across time. When an individual scored higher than expected on ADHD symptoms at T1, the same individual scored lower on family climate at $\mathrm{T} 2$. However, the opposite pattern was found between $\mathrm{T} 2$ and $\mathrm{T} 3$, where an individual with a higher than expected score on ADHD symptoms at $\mathrm{T} 2$ predicted a more favorable family climate at T3. However, changes in family climate had no lagged effects on changes in ADHD symptoms over time.

\section{Discussion}

The current study examined whether bidirectional associations between ADHD symptoms and the family and school climate were moderated by the plasticity genes $D R D 4$ and 5-HTTLPR across adolescence (mean ages 11, 13.5, and 16 years) in a large pooled population and clinic-referred sample. We did not find genetic moderation by the DRD4 or 5-HTTLPR genotype, neither at the between-person nor the within-person level. Independent from the $D R D 4$ and 5-HTTLPR genotype, we found important trait associations (i.e., between-person level) between ADHD and the family and school climate which indicated that adolescents with higher stable ADHD symptom levels lived in a less favorable family climate, and experienced a less favorable school climate across adolescence. Moreover, our results suggest causal effects between ADHD symptoms and the family climate (i.e., within-person level). That is, ADHD symptoms at age 11 predicted a less favorable family climate at the age of 13.5, while ADHD symptoms at age 13.5 predicted a more favorable family climate at age 16 . No evidence was found for family climate altering ADHD symptoms over time, nor for change processes between ADHD and school climate at the within-person level.

Using an advanced methodological approach that separates between-person differences from within-person processes, we found that ADHD symptoms and family climate were predominantly associated at the between-person level (i.e., the stable trait) compared to the within-person level. The link between ADHD symptoms and a less favorable family climate is consistent with previous literature [11, 12, 63], but does not inform us about the within-person changes that may take place during adolescence. Based on our findings between ADHD symptoms and family climate on the within-person level (i.e., in change over time) we found some evidence on prospective change in the link between ADHD symptoms and the family climate across adolescence. The findings that relate to change yielded two important conclusions about possible causal processes between ADHD symptoms and family climate. First, we found evidence, in line with the results of the between-person level, that ADHD symptoms at age 11 prospectively predicted a lower family climate at age 13.5 . On top of the stable characteristics between ADHD symptoms and family climate at the between-person level, high ADHD symptom levels predicted an even worse family climate 2.5 years later. However, the converse held later in adolescence, such that ADHD symptoms at age 13.5 predicted a more favorable family climate at age 16 years. This latter finding may at first glance seem unexpected, given that previous literature showed lower quality of family life among older youth, and high caregiver strain in families with ADHD [64]. It has to be kept in mind, however, that little is known about within person change processes, and that we also confirm this negative association between ADHD symptoms and family climate as being consistently present. There are two possible explanations for the unexpected finding which may be driven by those with or without ADHD symptoms. One explanation is that this finding might be a result of normative adolescent development, as adolescents spent less time at home [65] resulting in less parenting strain especially in families with ADHD. A second explanation again related to normative development would be that the positive effect of ADHD on family climate in the later phase of adolescence is in particular driven by the typically developing part of the sample without ADHD symptoms. That is, parents of adolescents without ADHD, at the most intense period of puberty when hormonal changes contribute to greater mood disruptions [66], may see the family climate as changing for worse. This in contrast with parents of children with ADHD who have been exposed to difficult behavior for a long time may actually during puberty not experience any surplus change for worse. Although our findings clearly need replication, and the explanations offered for our findings are currently speculative, they illustrate that, by distinguishing stable traits (i.e., between-person level) from change processes that occur between adolescents and their families (i.e., within-person level [43, 44]), more valid estimates of dynamic processes between the individual and his or her environment can be obtained. Future studies, using larger numbers of adolescents with and without ADHD are required to investigate to which extent effects (if replicated) are explained by ADHD or non ADHD individuals.

The second important finding related to processes over time is that we did not find evidence for possible causal effects of family climate on ADHD symptoms. That is, worsening of family climate did not increase ADHD symptoms or, conversely, improvement in family climate did not lead to reductions in ADHD symptoms. This contrasts with the suggestion of Johnston and Mash [67] that negative family relations might influence the continuation of ADHD symptoms, 
or, with findings from a meta-analysis of Coates et al. [68], showing the attenuation of ADHD following parent training intervention. But again, the existing literature has so far documented between person associations without disentangling the stable status quo from the change processes. These findings from the literature may thus be consistent with our stable findings that positive family climate co-occurs with less ADHD symptoms (or negative family environment with more ADHD symptoms). Alternatively, our null-finding may reflect the observational study design with large time lags of 2-3 years between measurements. Positive changes in the family climate may be more likely and, therefore, more easily detected, following treatment interventions A second alternative explanation is that the parenting environment, which is part of the family climate, is more critical in childhood than in adolescence [69]. It is, therefore, possible that the family climate influences ADHD symptoms especially at younger ages than examined here. Overall, our findings should be replicated.

Our finding of higher stable ADHD symptoms correlated with a less positive school climate across adolescence at the between-person level is in line with previous studies documenting an association between a good school climate and fewer student- and teacher reported internalizing and externalizing problems [70, 71, 72 in press]. However, there were no directional effects on the within-person level between ADHD symptom levels and the school climate in our study. While this may indicate that the two are not causally linked across adolescence, an alternative explanation for not finding these cross-lagged dynamical effects in the current study may lie in the large time lag, which might not capture reciprocal person- environment change. That is, it is to be expected that, compared to the family environment, there is a multitude of changes during two measurement waves, including changing peers and teachers. In light of these constantly changing circumstances in the adolescent's life outside the family environment, the absence of effects may indicate that the school climate is too distal and has changed too much to be of influence 2-3 years later. Vice versa, adolescence is a phase of considerable change in ADHD symptoms. The impulsive ADHD symptoms at for example age 11 may have receded at age 13.5 and may play no role in the renewed school environment at age 13.5. We recommend that causal effects of a positive school environment on ADHD symptoms be studied at smaller time intervals.

In contrast to previous studies (e.g., [33, 34]), adolescents with the DRD4 7-repeat or being homozygous for the S-allele of the 5-HTTLPR were not more responsive to the family or school environment in a 'for better and worse' manner. Thus, our study found no support for the differential susceptibility hypothesis. Previous studies on differential susceptibility have focused mostly on differences between individuals rather than the processes of change as they take place within the lives of an individual (i.e., withinperson level), and have not applied the RI-CLPM model which separates these two levels. Thus, in so far as our data would show support for differential susceptibility, based on the literature we did expect this to become apparent at the between- subject level, while potential effects at the withinsubject level would be novel. We had hoped that our developmental perspective would elucidate conflicting results especially about the 'risk' variant of the DRD4 genotype [37-39]. The absence of $\mathrm{G} \times \mathrm{E}$ effects could be due to the lack of power despite a relatively large sample size of almost 2000 participants. It could also be argued that the absence of $\mathrm{G} \times \mathrm{E}$ associations between ADHD symptoms and both family and school climate indicates these associations do not exist. There is a strong publication bias towards positive findings in the $\mathrm{G} \times \mathrm{E}$ literature [73], which might result in the absence of comparable (i.e., null-finding) published $\mathrm{G} \times \mathrm{E}$ studies.

\section{Strengths and limitations}

A strength of this study was the use of a large, longitudinal dataset and the application of an advanced methodological approach that separates between-person (i.e., stable trait levels) and within-person (i.e., causal processes) associations, providing clear evidence for links between ADHD symptoms and both family and school climate independent from the DRD4 and 5-HTTLPR genotypes across adolescent development. Some limitations should be taken into account when interpreting the current findings. First, assessment of the family climate as reported by parents does not necessarily inform us how adolescents themselves experienced the family climate. Another disadvantage of relying on parent reports of the family climate is that method variance may in part explain the associations with ADHD symptom levels (as these were also rated by the parents). However, it has been found that parent-reports of the home environment are well in line with child-reports [74]. Nevertheless, future research could benefit from self-ratings of both the family and school climate and the assessment of ADHD symptoms by at least two independent evaluators in different contexts. Second, the rating of the school climate was a compound measure of items relating to peers and teachers. This may have concealed parts of the effects (peers and teachers may not be equally important to adolescents). We also cannot be certain about the extent in which Positive Illusory Bias may have been involved in our school climate rating, despite our selection of the least subjective items. Third, adolescents are embedded in multiple other contexts than the family and school (e.g., sports team) that might affect ADHD symptoms across adolescence and which need to be included in future research. Fourth, while we controlled for ADHD medication, for a better understanding of causal processes 
at the within-person level other factors that are subjective to change (e.g., time spent outside home) should be incorporated as covariates in future investigations. Finally, it should be noted that present findings on the full spectrum of ADHD symptoms in adolescents may not generalize to clinical samples selected for being diagnosed with ADHD, or to other age groups.

\section{Conclusions}

Our study provides support that adolescents with ADHD symptoms and a less favorable family and school climate are tightly interwoven, as shown by stable between-person differences across adolescence. Moreover, within-person changes over time point to a causal role of ADHD symptoms on the family climate. These effects were independent from both the DRD4 and 5-HTTLPR genotype; thus, no evidence for differential susceptibility to the environment was found. To the extent that our findings on change processes may seem, unexpected, it is important to repeat that the existing knowledge base is confounded by stable associations between ADHD symptoms and family climate which have not been partialled out in previous studies. We recommend replication of our study applying the RI-CLPM to tease stable associations and change processes apart.

\section{Compliance with ethical standards}

Conflict of interest Jan K. Buitelaar has been a consultant to/member of advisory board of/and/or speaker for Janssen Cilag BV, Eli Lilly, Lundbeck, Takeda/Shire, Roche, Medice, Novartis, and Servier. He has received research support from Roche and Vifor. He is not an employee or a stock shareholder of any of these companies. He has no other financial or material support, including expert testimony, patents, and royalties. The other authors have no conflicts of interest.

Open Access This article is distributed under the terms of the Creative Commons Attribution 4.0 International License (http://creativeco mmons.org/licenses/by/4.0/), which permits unrestricted use, distribution, and reproduction in any medium, provided you give appropriate credit to the original author(s) and the source, provide a link to the Creative Commons license, and indicate if changes were made.

\section{References}

1. American Psychiatric Association (2013) Diagnostic and statistical manual for mental disorders, 5th edn. American Psychiatric Association, Arlington

2. Döpfner M, Hautmann C, Görtz-Dorten A, Klasen F, RavensSieberer U, The BELLA Study Group (2015) Long-term course of ADHD symptoms from childhood to early adulthood in a community sample. Eur Child Adolesc Psychiatry 24:665-673

3. Musser ED, Karalunas SL, Dieckman N, Peris TS, Nigg JT (2016) Attention-deficit/hyperactivity disorder developmental trajectories related to parental expressed emotion. J Abnorm Psychol 125:182-195

4. Tandon M, Tillmann R, Agrawal A, Luby J (2016) Trajectories of ADHD severity over 10 years from childhood into adulthood. Atten Defic Hyperact Disord 8:121-130

5. Brinksma DM, Hoekstra PJ, Van den Hoofdakker B, De Bildt A, Buitelaar JK, Hartman CA, Dietrich A (2017) Age-dependent role of pre- and perinatal factors in interaction with genes on ADHD symptoms across adolescence. J Psychiatr Res 90:110-117

6. Pingault J, Viding E, Galéra C, Greven CU, Zhen Y, Plomin R, Rijsdijk F (2015) Genetic and environmental influences on the developmental course of attention-deficit/hyperactivity disorder symptoms from childhood to adolescence. JAMA Psychiatry 72:651-658

7. Miranda A, Colomer C, Fernández MI, Presentación MJ, Roselló B (2017) Analysis of personal and family factors in the persistence of attention deficit hyperactivity disorder: results of a prospective follow-up study in childhood. PLoS One. https:// doi.org/10.1371/journal.pone.0128325

8. Roy A, Hechtman L, Arnold LE, Sibley MH, Molina BSG, Swanson JM, Howard AL, MTA Cooperative Group (2016) Childhood factors affecting persistence and desistence of attention-deficit/hyperactivity disorder symptoms in adulthood: results from the MTA. J Am Acad Child Adoelsc Psychiatry 55:937-944

9. Babinski DE, Pelham WE Jr, Molina BSG, Gnagy EM, Waschbusch DA, Wymbs BT, Sibley MH, Derefinko KJ, Kuriyan AB (2016) Maternal ADHD parenting and psychopathology among mothers of adolescents with ADHD. J Atten Disord 20:458-468

10. Biederman J, Milberger S, Faraone SV, Kiely K, Guite J, Mick E, Ablon JS, Warburton R, Reed E, Davis SG (1995) Impact of adversity on functioning and comorbidity in children with attention-deficit hyperactivity disorder. J Am Acad Child Adolesc Psychiatry 34:1495-1503

11. Brown RT, Pacini JN (1989) Perceived family functioning marital status and depression in parents of boys with attention deficit disorder. J Learn Disabil 22:581-587

12. Gau SSF, Chang JPC (2013) Maternal parenting styles and mother-child relationship among adolescents with and without persistent attention-deficit/hyperactivity disorder. Res Dev Disabil 34:1581-1594

13. Schroeder VM, Kelley ML (2009) Associations between family environment parenting practices and execute functioning of children with and without ADHD. J Child Fam Stud 18:227-235

14. Keown LJ (2012) Predictors of boys' ADHD symptoms from early to middle childhood: the role of father-child and mother-child interactions. J Abnorm Child Psychol 40:569-581

15. Auerbach JG, Zilberman-Hayun Y, Atzaba-Poria N, Berger A (2017) The contribution of maternal ADHD symptomatology, maternal DAT1, and home atmosphere to child ADHD symptomatology at 7 Years of Age. J Abnorm Child Psychol 45:415-427

16. Eccles JS, Midgely C, Wigfield A, Buchanan CM, Reuman D, Flanagan C, Maclver D (1993) Development during adolescence: the impact of stage-environment fit on young adolescents' experiences in schools and in families. Am Psychol 48:90-101

17. Viner RM, Ozer EM, Denny S, Marmot M, Resnick M, Fatusi A, Curri C (2012) Adolescence and the social determinants of health. Lancet 379:1641-1652

18. Hawes D, Dadds M, Frost A, Russell A (2013) Parenting practices and prospective levels of hyperactivity/inattention across early and middle childhood. J Psychopathol 35:273-282

19. Demmer DH, Puccio F, Stokes MA, McGillivray JA, Hooley M (2017) The influence of child gender on the prospective relationships between parenting and child ADHD. J Abnorm Child Psychol 46:113-125 
20. Lifford KJ, Harold GT, Thapar A (2008) Parent-child relationships and ADHD symptoms: a longitudinal analysis. J Abnorm Child Psychol 36:285-296

21. Breaux RP, Brown HR, Harvey EA (2017) Mediators and moderators of the relation between parental ADHD symptomatology and the early development of child ADHD and ODD symptoms. J Abnorm Child Psychol 45:443-456

22. Moroney E, Tung I, Brammer WA, Peris TS, Lee SS (2017) Externalizing outcomes of youth with and without ADHD: time-varying prediction by paternal ADHD and mediated effects. J Abnorm Child Psychol 45:457-470

23. Chronis AM, Jones HA, Raggi VL (2006) Evidence-based psychosocial treatments for children and adolescents with attentiondeficit/hyperactivity disorder. Clin Psychol Rev 26:486-502

24. Hoza B, Mrug S, Gerdes AC, Hinshaw SP, Bukowski WM, Gold JA, Arnold LE (2005) What aspects of peer relationships are impaired in children with attention-deficit/hyperactivity disorder? J Consult Clin Psychol 73:411-423

25. Sciberras E, Ohan J, Anderson V (2012) Bullying and peer victimization in adolescent girls with attention-deficit/hyperactivity disorder. Child Psychiatry Hum Dev 43:254-270

26. Taylor AL, Saylor C, Twyman K, Macias M (2010) Adding insult to injury: bullying experiences of youth with attention deficit hyperactivity disorder. Child Health Care 39:59-72

27. Becker SP, Fite PJ, Luebbe AM, Stoppelbein L, Greening L (2012) Friendship intimacy exchange buffers the relation between ADHD symptoms and later social problems among children attending an after-school care program. J Psychopathol Behav Assess 35:142-152

28. Muller C (2001) The role of caring in the teacher-student relationship for at-risk students. Sociol Inq 71:241-255

29. Sherman J, Rasmussen C, Baydala L (2008) The impact of teacher factors on achievement and behavioural outcomes of children with attention deficit/hyperactivity disorder (ADHD): a review of the literature. Edu Res 50:347-360

30. Greene RW, Beszterczey SK, Katzenstein T, Park K, Goring J (2002) Are students with ADHD more stressful to teach? J Emot Behav Disord 10:79-89

31. Belsky J, Bakermans-Kranenburg MJ, Van IJzendoorn MH (2007) For better and for worse: differential susceptibility to environmental influences. Curr Dir Psychol Sci 16:300-304

32. Ellis BJ, Boyce WT, Belsky J, Bakermans-Kranenburg MJ, Van IJzendoorn MH (2011) Differential susceptibility to the environment: an evolutionary-neurodevelopmental theory. Dev Psychopahtol 23:7-28

33. Bakermans-Kranenburg MJ, Van IJzendoorn MH (2011) Differential susceptibility to rearing environment depending on dopamine-related genes: new evidence and a meta-analysis. Dev Psychopathol 23:39-52

34. Belsky J, Pluess M (2009) Beyond diathesis stress: differential susceptibility to environmental influences. Psychol Bull 135:885-908

35. Belsky J, Pluess M (2013) Genetic moderation of early childcare effects on social functioning across childhood: a developmental analysis. Child Dev 84:1209-1225

36. Nikolas MA, Momany AM (2017) DRD4 variants moderate the impact of parental characteristics on child attention-deficit hyperactivity disorder: exploratory evidence from a multiplex family design. J Abnorm Child Psychol 45:429-442

37. DiLalla LF, Bersted K, John SG (2015) Peer victimization and DRD4 genotype influence problem behaviors in young children. J Youth Adolesc 44:1478-1493

38. Kretschmer T, Dijkstra JK, Ormel J, Verhulst FC, Veenstra R (2013) Dopamine receptor D4 gene moderates the effect of positive and negative peer experiences on later delinquency: the Tracking Adolescents' Individual Lives Survey study. Dev Psychopathol 25:1107-1117

39. De Laet S, Colpin H, Van Leeuwen K, Van Den Noortgate W, Claes S, Janssens A, Goossens L, Verschueren K (2016) Teacher-student relationships and adolescent behavioral engagement and rule-breaking behavior: the moderating role of dopaminergic genes. J Sch Psychol 56:13-25

40. Van IJzendoorn MH, Belsky J, Bakermans-Kranenburg MJ (2012) Serotonin transporter genotype 5HTTLPR as a marker of differential susceptibility? A meta-analysis of child and adolescent gene-by-environment studies. Transl Psychiatry. https:// doi.org/10.1038/tp.2012.73

41. Elmore AL, Nigg JT, Friderici KH, Jernigan K, Nikolas MA (2016) Does 5HTTLPR genotype moderate the association of family environment with child attention-deficit hyperactivity disorder symptomatology? J Clin Adolesc Psychol 45:348-360

42. Stenseng F, Li Z, Belsky J, Hygen BW, Skalicka V, Guzey IC, Wichstrøm L (2017) Peer problems and hyperactivity-impulsivity among Norwegian and American children: the role of 5-HTTLPR. Child Dev 89:509-524

43. Hamaker EL, Kuiper RM, Grasman RP (2015) A critique of the cross-lagged panel model. Psychol Methods 20:102-116

44. Keijsers L (2015) Parental monitoring and adolescent problem behaviors: how much do we really know? Int J Behav Dev 40:271-281

45. Berry D, Willoughby MT (2016) On the practical interpretability of cross-lagged panel models: rethinking a developmental workhorse. Child Dev 88:1186-1206

46. Shanahan MJ, Boardman JD (2009) Genetics and behavior in the life course: a promising frontier. In: Elder GH Jr, Giele JZ (eds) The craft of life course. The Guilford Press, New York, pp 215-235

47. De Winter AF, Oldehinkel AJ, Veenstra R, Brunnekreef JA, Verhulst FC, Ormel J (2005) Evaluation of non-response bias in mental health determinants and outcomes in a large in a large of non-response bias in mental health determinants and outcomes sample. Eur J Epidemiol 20:173-181

48. Oldehinkel AJ, Rosmalen JGM, Buitelaar JK, Hoek HW, Ormel J, Raven D, Reijneveld SA, Veenstra R, Verhulst FC, Vollebergh WA, Hartman CA (2015) Cohort profile update: the Tracking Adolescents' Individual Live Survey (TRAILS). Int J Epidemiol 44:76

49. Achenbach TM, Rescorla LA (2001) Manual for the ASEBA preschool forms \& profiles. University of Vermont Research Center for Children Youth \& Family, Burlington

50. Shaffer D, Fisher P, Lucas CF, Dulcan MK, Schwab-Stone ME (2000) NIMH Diagnostic Interview Schedule for Children version IV (NIMH DISC-IV): description differences from previous versions and reliability of some common diagnoses. J Am Acad Child Adolesc Psychiatry 39:28-38

51. Achenbach TM (1991) Manual for the child behavior checklist/4-18 and 1991 profile. University of Vermont Department of Psychiatry, Burlington

52. Verhulst FC, Achenbach TM (1995) Empirically based assessment and taxonomy of psychopathology: cross-cultural applications a review. Eur Child Adolesc Psychiatry 4:61-76

53. Epstein NB, Baldwin LM, Bishop DS (1983) The McMaster family assessment device. J Marital Fam Ther 9:171-180

54. Ormel J (2002) Social production function (SPF) theory as an heuristic for understanding developmental trajectories and outcomes. In: Pulkkinen L, Caspi A (eds) Paths to successful development: personality in the life course. University Press, Cambridge, pp 353-379

55. Ormel J, Lindenberg S, Steverink N, Vonkorff M (1997) Quality of life and social production functions: a framework for understanding health effects. Soc Sci Med 45:1051-1063 
56. Owens JS, Goldfine ME, Evangelista NM, Hoza B, Kaiser N (2007) A critical review of self-perceptions and the positive illusory bias in children with ADHD. Clin Child Fam Psychol Rev 10:335-351

57. Miller SA, Dykes DD, Polesky HF (1988) A simple salting out procedure for extracting DNA from human nucleated cells. Nucleic Acids Res 16:1215

58. Hu X-Z, Lipsky RH, Zhu G, Akhtar LA, Taubman J, Greenberg BD, Xu K, Arnold PD, Richter MA, Kennedy JL, Murphy DL, Goldman D (2006) Serotonin transporter promoter gain-of-function genotypes are linked to obsessive-compulsive disorder. Am J Hum Genet 78:815-826

59. Muthén LK, Muthén BO (1998-2010) Mplus user's guide, 6th en. Muthén \& Muthén, Los Angeles

60. Hu LT, Bentler PM (1999) Cutoff criteria for fit indexes in covariance structure analysis: conventional criteria versus new alternatives. Struct Equ Model 6:1-55

61. Kline RB (2005) Principles and practice of structural equation modeling, 2nd edn. The Guilford Press, New York

62. Satorra A, Bentler PM (2001) A scaled difference Chi square test statistic for moment structural analysis. Psychometrika 66:507-514

63. Foley M (2011) A comparison of family adversity and family dysfunction in families of children with attention deficit hyperactivity disorder (ADHD) and families of children without ADHD. J Spec Pediatr Nurs 16:39-49

64. Haber MS, Cook JR, Kilmer RP (2012) Perceptions of family environment and wraparound processes: associations with age and implications for serving transitioning youth in systems of care. Am J Community Psychol 49:454-466
65. Larson RW, Richards MH, Moneta G, Holmbeck GC (1996) Changes in adolescents' daily interactions with their families from ages 10 to 18: disengagement and transformation. Dev Psychol 32:744-754

66. Arnett JJ (1999) Adolescent storm and stress reconsidered. Am Psychol 54:317-326

67. Johnston C, Mash EJ (2001) Families of children with attentiondeficit/hyperactivity disorder: review and recommendations for future research. Clin Child Fam Psychol Rev 4:183-207

68. Coates J, Taylor JA, Sayal K (2015) Parenting interventions for ADHD: a systematic literature review and meta-analysis. J Atten Disord 19:831-843

69. Sameroff AJ (2010) A unified theory of development: a dialectic integration of nature and nurture. Child Dev 81:6-22

70. Hendron M, Kearney CA (2016) School climate and student absenteeism and internalizing and externalizing behavioral problems. Child Sch 38:109-116

71. Kuperminc GP, Leadbeater BJ, Blatt SJ (2001) School social climate and individual differences in vulnerability to psychopathology among middle school students. J Sch Psychol 39:141-159

72. Li JJ (2019) Assessing phenotypic and polygenic models of ADHD to identify mechanisms of risk for longitudinal trajectories of externalizing behaviors. J Child Psychol Psychiatry 60:1191-1199

73. Duncan LE, Keller MC (2011) A critical review of the first 10 years of candidate gene-by-environment interaction research in psychiatry. Am J Psychiatry 168:1041-1049

74. Hanscombe K, Haworth CMA, Davis OSP, Jaffee SR, Plomin R (2011) Chaotic homes and school achievement: a twin study. J Child Psychol Psychiatry 52:1212-1220 